\title{
A indicação geográfica de produtos: um estudo sobre sua contribuição econômica no desenvolvimento territorial
}

\author{
A geographical indication of goods: a study of their economic contribution in \\ territorial development
Indicación geográfica de productos: un estudio de su contribución económica en el desarrollo territorial
Indication géographique des marchandises: une étude de leur contribution économique au développement territorial \\ Giovane José Maiorki* \\ (giovane@unc.br) \\ Valdir Roque Dallabrida* \\ (valdir@unc.br)
}

Recebido em 20/03/2014; revisado e aprovado em 15/09/2014; aceito em 15/10/2014

DOI: http://dx.doi.org/10.1590/151870122015101

\begin{abstract}
Resumo: O registro de produtos com Indicação Geográfica (IG) vem crescendo no Brasil. Estes são produzidos em regiões onde é possível identificar certos diferenciais, que estão relacionados com local de produção, solo, clima, forma de produção e colheita. Essa especificidade tende a contribuir com a agregação de valor a esses produtos, com impactos no desenvolvimento territorial. O objetivo deste trabalho foi avaliar a contribuição econômica da Indicação Geográfica de produtos no desenvolvimento territorial. Nos procedimentos metodológicos, o presente trabalho se classifica como bibliográfico e estudo de caso, conduzido por meio do método científico hipotético-dedutivo. Para a coleta de dados, foram realizadas pesquisas documentais e entrevistas com associados e dirigentes das associações que detêm o ato declaratório do Instituto Nacional de Propriedade Industrial, a Asprovinho, localizada no estado do Rio Grande do Sul, e a Progoethe, localizada ao sul do estado de Santa Catarina, sendo que, em ambas, o produto é o vinho. Com os resultados obtidos na revisão da literatura e nas pesquisas de campo, foi possível identificar a importância da Indicação Geográfica como vetor do desenvolvimento de territórios e regiões, salientando que isso não ocorre de forma autônoma, mas sim com a contribuição da sociedade civil e dos setores da economia que fazem parte do objeto da Indicação Geográfica.
\end{abstract}

Palavras-chave: Indicação Geográfica. Território. Desenvolvimento Territorial.

Abstract: The registration of products with Geographical Indication has been growing in Brazil. These are produced in regions where it is possible to identify certain differences, which are related to the production location, soil, climate, and crop production form, giving it a differential. This specification tends to contribute in adding value to these products, with impacts on regional development. The aim of this work was to evaluate the economic contribution of Geographical Indication products in territorial development. In the methodological procedures, this work qualifies as bibliographic and case study, conducted through hypothetical-deductive scientific method. For data collection, it was carried out documentary researches and interviews with associates and directors of associations who own the declaratory act of the National Institute of Industrial Property, Asprovinho, located in the state of Rio Grande do Sul and Progoethe, located in the south of the state of Santa Catarina, and in both the product is the wine. With the results obtained in the literature review and the field research, it was possible to identify the importance of Geographical Indication as a vector of development of territories and regions, stressing that it does not occur independently, but with the contribution of the civil society and the economic sectors that are part of the object of the Geographical Indication.

Key words: Geographical Indication. Territory. Territorial Development.

Résumé: L'enregistrement des produits Indication Géographique est en croissance au Brésil. Ils sont produits dans les régions lesquels il est possible d'identifier certaines différences, qui sont liées à la localisation de la production, le sol, le climat, forme de la production et de la récolte. Cette spécifique tend à contribuer au ajouter de la valeur à ces produits, avec des effets quant au développement territoriale. Les procédures ordre méthodologique, cet travaux se qualifie comme bibliographique et l'étude de cas, menée par la méthode scientifique hypothético-déductive. Pour la collecte des données, ont été effectuées des recherches documentaires et d'entretiens avec des associés et des directeurs d'associations titulaires l'acte déclaratoires de l'Institut national de la propriété industrielle, la Asprovinho, situé dans l'État de Rio Grande do Sul et Progoethe situé au sud de l'État de Santa Catarina, et dans les deux le produit que est du vin. Avec les résultats obtenus à dans l'examen de la littérature et de la recherche sur le terrain, il a été possible d'identifier l'importance de l'Indication Géographique comme un vecteur de développement des territoires et des régions, en soulignant que cela ne se produit pas de façon indépendante, mais à contribution de la société civile et autre secteurs de l'économie faisant partie de l'objet de l'Indication Géographique.

Mots-clés: Indication géographique. Territoire. Développement territorial.

\footnotetext{
* Universidade do Contestado, Santa Catarina, Brasil.
} 


\begin{abstract}
Resumen: El registro de los productos con Indicación Geográfica (IG) está creciendo en Brasil. Estos se producen en las regiones en las que es posible identificar ciertas diferencias, que están relacionados con la localización de la producción, suelo, clima, forma de producción y la cosecha. Esta especificidad tiende a contribuir a agregar valor a estos productos, con impactos en el desarrollo regional. El objetivo de este estudio fue evaluar la contribución económica de la Indicación Geográfica de productos en el desarrollo territorial. En los procedimientos metodológicos, este trabajo se califica como bibliográfico y el estudio de caso, realizado a través del método científico hipotéticodeductivo. Para la recolección de datos, se realizaron búsquedas documentales y entrevistas con los socios y directivos de las asociaciones que tienen el acto declarativo del Instituto Nacional de la Propiedad Industrial, el Asprovinho, ubicada en el estado de Rio Grande do Sul y la Progoethe, ubicada en el sur del estado de Santa Catarina, y en ambos el producto es el vino. Con los resultados obtenidos en la revisión de la literatura y la investigación de campo, fue posible identificar la importancia de la Indicación Geográfica como vector de desarrollo de los territorios y regiones, haciendo hincapié en que esto no ocurre de manera independiente, pero con la contribución de la sociedad civil y sectores de la economía que son parte del objeto de la Indicación Geográfica.

Palabras clave: Indicación Geográfica. Territorio. Desarrollo Territorial.
\end{abstract}

\section{Introdução}

A Indicação Geográfica (IG) refere-se a uma qualidade atribuída a um produto originário de um território cujas características são inerentes a sua origem geográfica. Representa uma qualidade relacionada ao meio natural ou a fatores humanos, que lhes atribuem notoriedade e especificidade territorial.

O registro de produtos com IG no Brasil é feito pelo Instituto Nacional da Propriedade Industrial (INPI), e vem crescendo nos últimos cinco anos. Os fatores para que um produto adquira certa notoriedade estão relacionados com o local de produção, em função do solo, do clima, da forma de produção e colheita, ou com outras características que lhe confiram um diferencial. Essa especificidade tende a contribuir com a agregação de valor a esses produtos, o que pode gerar maior retorno financeiro aos atores envolvidos, com possíveis impactos no desenvolvimento territorial.

Nesse sentido, em investigação que resultou no presente artigo, buscou-se responder a seguinte questão: qual a contribuição econômica da Indicação Geográfica de produtos no desenvolvimento territorial? Partiu-se de uma hipótese de trabalho: se os produtos que possuem Indicação Geográfica são capazes de gerar um incremento no preço de venda e com isso contribuir para a agregação de renda, a Indicação Geográfica pode contribuir economicamente com o desenvolvimento de um território ${ }^{1}$.

\footnotetext{
${ }^{1}$ Este artigo sintetiza estudos realizados na dissertação no Programa de Mestrado em Desenvolvimento Regional, na Universidade do Contestado (Santa Catarina, Brasil), sendo, o primeiro e o último autor, respectivamente, mestrando e orientador.
}

O estudo realizado teve como campo de observação duas experiências de IG do setor vinícola do sul do Brasil. Trata-se de uma pesquisa ainda de caráter exploratório, sustentada no estudo de dois casos, através de visitas de observação e entrevistas com atores envolvidos. Complementarmente, a consulta à bibliografia recente também serviu de referência.

Estudos dessa natureza tornam-se necessários, visto que no Brasil o debate sobre produtos com IG é recente, em relação aos países da Europa e Ásia, tendo seus primeiros registros ocorridos há pouco mais de dez anos. A iniciativa do estudo foi um ponto positivo, pois trouxe algumas evidências e apontou diferentes desafios, os quais, por conseguinte, é que exigirão novos estudos.

Além desta introdução, o texto foi estruturado em cinco partes: (1) retrospecto histórico sobre Indicação Geográfica; (2) aspectos teóricos e conceituais dos temas relacionados ao objeto da pesquisa; (3) questões de ordem metodológica e caracterização do objeto de estudo; (4) resultados da pesquisa quanto à percepção dos entrevistados; (5) última parte, com considerações finais sobre possíveis impactos de uma IG no desenvolvimento de um território, levando-se em consideração a dimensão econômica, com base nas duas experiências estudadas.

\section{Indicações geográficas: retrospecto histó- rico e contextualização}

Mundialmente a Indicação Geográfica, segundo Kakuta et al. (2006), ocorre desde a era Romana e na antiga Grécia (século 4 a.C). Na primeira, pela produção de vinhos e, na segunda, pelos mármores de Carrara, como 
uma forma de proteger os produtos e atribuir punição aos que descumprissem as normas. Para Pimentel (2013), ao utilizar o sistema de propriedade intelectual, as nações buscam por meio deste o crescimento e desenvolvimento, através de recursos que podem ser explorados como ativos econômicos.

Segundo Gontijo (2005), foi o acordo de Paris um importante marco regulatório. Mundialmente, no ano de 1994, foi instituído o marco legal, quando a Organização Mundial do Comércio (OMC) reconheceu o conceito de Indicação Geográfica, no acordo Trade-Related Aspects of Intellectual Property Rights (TRIPS). O Acordo TRIPS, segundo Ferreira et al. (2013, p. 128): "Tratava de questões ligadas ao comércio de bens cujo diferencial competitivo pudesse estar protegido por mecanismos de propriedade intelectual e que foi subscrito por todos os países que desejavam pertencer à $\mathrm{OMC}$, incluindo o Brasil, contando atualmente com 157 países".

$\mathrm{Na}$ Europa, segundo Sacco dos Anjos et al. (2013), é através do regulamento CE 2081/92 que são apresentados os dois tipos de certificação. A primeira referente à Denominação de Origem Protegida (DOP), e a segunda, a Indicação Geográfica Protegida (IGP). Já o regulamento CE 2082/92 trata da certificação de características específicas ou especialidades tradicionais garantidas, sendo que estas contemplam apenas produtos agroalimentares. Para tais autores, há diferenças entre as experiências de IG europeias e as brasileiras. Enquanto nos países europeus incluem-se apenas alimentos; no Brasil a certificação inclui vários produtos, como alimentos, calçados, mármores e até serviços.

Mas há outras diferenças entre o Brasil e a Europa em relação às IGs. A primeira está no fato de existir uma aprovação transitória e, somente após esta, pela Comissão Europeia de Agricultura e Desenvolvimento, obtém-se o registro definitivo. No Brasil, ocorre em caráter definitivo pelo INPI, sem a necessidade e certificação prévia, sendo um processo único. Para Sacco dos Anjos et al. (2013), a segunda é a existência das empresas do setor privado ou as autoridades públicas, que são entidades certificadoras de cada país Europeu, que fiscalizam o cumprimento do Caderno de Normas, e estas são igualmente subordinadas aos regimes de controle e fiscalização, o que não existe no modelo brasileiro.

O Brasil, mesmo sendo país signatário da Convenção da União de Paris (CUP) desde 1883, somente após o acordo de Madrid, em 1975, passou a repreender as falsas indicações de procedência (FERREIRA et al., 2013). No ano 1967, é promulgado o Código de Propriedade Industrial (CPI) brasileiro, com o qual se passa a reconhecer e a proteger a produção nacional contra a falsificação dos produtos e da procedência dos mesmos.

Atualmente, no Brasil, a Lei ${ }^{\circ} 9279$, de 14 de maio de 1996, é que regulamenta os direitos e obrigações sobre propriedade intelectual. A Indicação Geográfica está disciplinada no Título IV, nos Art. 176 a 182. O parágrafo único do Art. 182 estabelece que o órgão responsável pela concessão e registro das Indicações Geográficas é o INPI.

\subsection{A Indicação Geográfica (IG) no Brasil}

A Indicação Geográfica constitui um processo, como o próprio nome diz, de identificar um produto ou serviço de determinado território. É um procedimento similar ao registro civil de uma pessoa, que lhe garante direitos civis estabelecidos pela Constituição.

A identificação de produtos e serviços com Indicação Geográfica garante a esses também direitos civis. Ferreira et al. (2013) caracterizam IG como um direito exclusivo ligado à propriedade industrial, com natureza e uso coletivo e vinculado a uma região específica.

Outros autores também conceituam Indicação Geográfica. Para Gollo e Castro (2007), é um produto originário do território cujas características são atribuídas à origem geográfica. Já Pimentel (2013) define como uma propriedade intelectual do tipo industrial, coletiva e exclusiva a produtores de determinado local. Dentre os principais objetivos da Indicação Geográfica, segundo o autor, está o desenvolvimento econômico do território, por meio de vinculação do produto, sua qualidade e especificidade em relação ao território onde este é produzido.

Boechat e Alves (2011) evidenciam a importância da IG na valorização do patrimônio cultural e do turismo, o que, segundo eles, pode trazer uma maior abertura de mercado, 
a padronização dos produtos e o estímulo ao agroturismo. Para Kakuta et al. (2006), os benefícios do uso da Indicação Geográfica são a proteção ao patrimônio, o desenvolvimento rural, a promoção e facilidades de exportação e o desenvolvimento. O registro no INPI é considerado, de modo geral, como o ponto de chegada, mas deveria ser visto como ponto de partida para fomentar novas alianças entre turismo, serviços e demais setores. Nesse sentido, entende-se que a certificação de uma IG deve ter início com a intenção de transformar um recurso em um ativo com especificidade territorial. Para tanto, é necessária a mobilização de pessoas para formar uma associação ou cooperativa e assim obter o ato declaratório de IG.

No Brasil, as experiências de IG podem ser registradas como Indicação de Procedência ou Denominação de Origem.

\subsubsection{Indicação de Procedência}

A definição de Indicação de Procedência (IP) está prevista no Art. 177 da Lei ${ }^{\circ}$ 9.279/1996. A IP estabelece o local, o território onde foi produzido, sem que este esteja relacionado especificamente com fatores de diferenciação em relação à qualidade deste produto com outros similares. O seu diferencial é o modo de produção e o aspecto cultural que o fazem reconhecido como de qualidade diferenciada em relação aos demais. Essa diferenciação pode gerar um valor de venda maior.

De acordo com o INPI, na data de 25 de janeiro de 2014, no Brasil existiam 30 registros de Indicação de Procedências, todas nacionais. O estado de Minas Gerais aparece com sete registros, o Rio Grande do Sul com seis e o estado do Espírito Santo com três indicações. As demais experiências de IG são de outros estados brasileiros que possuem apenas uma Indicação de Procedência.

\subsubsection{Denominação de Origem}

O Registro de Denominação de Origem (DO) está previsto no Art. 178 da Lei $\mathrm{n}^{\circ}$ 9.279/1996. A DO está relacionada com componentes físico-químicos encontrados nos produtos, que, devido às condições geográficas (solo e clima), não poderão ser encontradas em outras regiões, ou seja, a DO indica que o produto somente pode ser encontrado em determinada região, o que lhe confere uma personalíssima característica.

De acordo com o INPI (BRASIL, 2014), em maio de 2014, no Brasil existiam 16 registros de Denominação de Origem, das quais 08 eram nacionais.

\section{Indicação geográfica: concepções teóricas que fundamentam o tema}

Dentre as concepções teóricas que fundamentam a discussão sobre o tema Indicação Geográfica, algumas são fundamentais: a concepção de território, identidade e desenvolvimento territorial.

\subsection{Território e sua relação com a Indicação Geográfica}

Etimologicamente território vem do latim territorium, pedaço de terra apropriado, que transmite a ideia de poder, identidade e domínio.

Para Santos (1996, p. 51): “A configuração territorial é dada pelo conjunto formado pelos sistemas naturais existentes em um dado país ou numa dada área e pelos acréscimos que os homens superpuseram a esses sistemas naturais". Em outra obra, Santos (2007, p. 13) define território: “O lugar em que desembocam todas as ações, todas as paixões, todos os poderes, todas as forças, todas as fraquezas, isto é, onde a história do homem plenamente se realiza a partir das manifestações da sua existência".

Na concepção de Saquet e Silva (2008, p. 17): "O território corresponde aos complexos naturais e às construções/obras feitas pelo homem: estradas, plantações, fábricas, casas, cidades. O território é construído historicamente, cada vez mais, como negação da natureza natural". Já Para Pollice (2010, p. 8): "Em síntese, o território pode ser entendido como aquela porção do espaço geográfico na qual uma determinada comunidade se reconhece e se relaciona no seu agir individual ou coletivo [...]". Souza (2001, p. 111), assim conceitua território: " [...] todo espaço definido e delimitado por e a partir de relações de poder é um território, do quarteirão aterrorizado por uma gangue de jovens até o bloco constituído pelos países membros da OTAN". 
Na concepção de Haesbaert (2004, p. 79), “[...] o território pode ser conhecido a partir da imbricação de múltiplas relações de poder, do poder mais material das relações econômico-políticas ao poder mais simbólico das relações de ordem mais estritamente cultural". Em relação à forma de poder, para Haesbaert (2010), deve-se entender que não está se referindo a um poder material, mas os efeitos deste.

Para Haesbaert (2007), o território também possui uma forte ligação com a natureza e com os recursos nela existentes, configurando assim, junto com o homem, os costumes e a história, um dos elementos para a formação de um território.

Sobre a definição de território, assumese aqui uma conceituação referenciada em Dallabrida e Fernández (2008, p. 40). Para esses autores o território é entendido como:

Uma fração do espaço historicamente construída através das inter-relações dos atores sociais, econômicos e institucionais que atuam neste âmbito espacial, apropriada a partir de relações de poder sustentadas em motivações políticas, sociais, ambientais, econômicas, culturais ou religiosas, emanadas do Estado, de grupos sociais ou corporativos, instituições ou indivíduos.

A relação entre Indicação Geográfica e território é apresentada por Jeziorny (2009, p. 148): "Concluímos que as indicações geográficas e o território formam uma espécie de simbiose, pois não existe indicação geográfica sem o território, ao passo em que o próprio território pode se desenvolver por meio da construção de uma indicação geográfica".

Considerando as definições sobre território, de forma especial o argumento de que este se forma por uma relação de poder (SOUZA, 2001), e que não existe Indicação Geográfica sem território (JEZIORNY, 2009), fica implícito que a Indicação Geográfica é um processo de demarcação de um território, pois a declaração expedida pelo INPI define quais pessoas e em que locais podem se beneficiar da certificação de produtos ora produzidos.

\subsection{Identidade e Desenvolvimento Territorial}

Definido território como espaço delimitado pelas relações de poder, a identidade territorial é a expressão cultural e do estoque de fatores endógenos que identificam esse território. A identidade territorial, chamada por Pollice (2010) de identidade geográfica, é aquela que nasce da consciência coletiva das pessoas que habitam determinado território. Assim, somente se pode ter uma identidade territorial ou geográfica quando advém do desejo das pessoas de serem reconhecidas como atores desse processo de identificação. Quando a identidade territorial se dá pelo aspecto negativo de representação, essa identificação é feita por fontes externas, como por exemplo, pessoas que moram em regiões próximas à chamada "Cracolândia", em São Paulo. Os indivíduos que moram nessas regiões jamais vão se sentir como pessoas que moram no território da "Cracolândia". Por outro lado, quando a identificação é benéfica ou reforça o estoque cultural e os fatores endógenos do lugar, esta recebe contornos de notoriedade, como, por exemplo, o território do Vale dos Vinhedos no estado do Rio Grande do Sul.

Assume-se uma concepção de desenvolvimento territorial pautada em Dallabrida (2014): processo de mudança continuada, situado histórica e territorialmente, mas integrado em dinâmicas intraterritoriais, supraterritoriais e globais, sustentado na potenciação dos recursos e ativos (materiais e imateriais, genéricos e específicos) existentes no local, com vistas à dinamização socioeconômica e à melhoria da qualidade de vida da sua população.

Por fim, Pollice (2010) estabelece uma relação entre identidade e desenvolvimento territorial, conforme sintetizado no Quadro 1. 
Quadro 1 - Relações entre identidade territorial e desenvolvimento

\begin{tabular}{|c|c|}
\hline Indicador & Relação \\
\hline $\begin{array}{l}\text { Identidade e } \\
\text { valores sociais }\end{array}$ & $\begin{array}{l}\text { A identidade territorial tende a reforçar o poder normativo dos valores éticos e } \\
\text { comportamentais localmente compartilhados. Sobre o plano socioeconômico, } \\
\text { a presença destes valores e, sobretudo, o entrecruzamento deles, consente em } \\
\text { melhorar o nível de relação produtiva e comercial, favorecendo a manifestação } \\
\text { daquelas formas de colaboração competitiva que constituem o fundamento } \\
\text { das economias distritais. }\end{array}$ \\
\hline $\begin{array}{l}\text { Identidade e } \\
\text { transferência do } \\
\text { saber }\end{array}$ & $\begin{array}{l}\text { Manifesta-se um "apego afetivo" ao saber localmente determinado e uma } \\
\text { propensão mais forte que em outro lugar para a atualização deste patrimônio } \\
\text { cognitivo. }\end{array}$ \\
\hline $\begin{array}{l}\text { Identidade e } \\
\text { sentido de pertença }\end{array}$ & $\begin{array}{l}\text { Talvez este seja o exemplo mais emblemático da interação virtuosa entre iden- } \\
\text { tidade territorial e desenvolvimento local. O sentido de pertença constitui, de } \\
\text { fato, o cimento do sistema econômico-territorial e impele os atores locais a pre- } \\
\text { ferir, também na presença de algumas deseconomias, conter relações transa- } \\
\text { cionais e colaborativas no interior do âmbito local. }\end{array}$ \\
\hline $\begin{array}{l}\text { Identidade e } \\
\text { autorreprodução }\end{array}$ & $\begin{array}{l}\text { Melhorar o nível de relação produtiva e comercial, favorecendo a manifestação } \\
\text { daquelas formas de colaboração competitiva que constituem o fundamento } \\
\text { das economias distritais. }\end{array}$ \\
\hline $\begin{array}{l}\text { Identidade e } \\
\text { política }\end{array}$ & $\begin{array}{l}\text { A relação entre identidade e política é muito forte, tende a crescer, no âmbito } \\
\text { da arena política, o nível de convergência sobre os temas e o desenvolvimento } \\
\text { de atores locais adequando-os às exigências do território e evitando que resulte } \\
\text { numa desorganização dos equilíbrios locais. }\end{array}$ \\
\hline $\begin{array}{l}\text { Identidade e } \\
\text { valorização dos } \\
\text { recursos territoriais }\end{array}$ & $\begin{array}{l}\text { O desenvolvimento endógeno se substancia na capacidade da comunidade lo- } \\
\text { cal de "colocar em valor" o território e, em particular, aqueles recursos não } \\
\text { localizáveis que, além de constituir elemento de diferenciação, podem tornar- } \\
\text { se, em termos projetivos, certos plus competitivos em torno dos quais se pode } \\
\text { construir a estratégia de desenvolvimento local. }\end{array}$ \\
\hline $\begin{array}{l}\text { Identidade e } \\
\text { sustentabilidade }\end{array}$ & $\begin{array}{l}\text { Os sentimentos identitários determinam em nível local um apego afetivo aos va- } \\
\text { lores paisagísticos e culturais do território que tende, por sua vez, a traduzir-se } \\
\text { na adoção de comportamentos individuais e coletivos voltados à tutela e à valo- } \\
\text { rização daqueles valores. A presença de uma forte identidade territorial favorece } \\
\text { a maturação de modelos de desenvolvimento sustentável, enquanto este se fun- } \\
\text { da sobre a valorização, especificidade dos lugares; valorização que é tanto mais } \\
\text { eficaz quanto maior é o envolvimento ativo da comunidade local. Além disso, a } \\
\text { "sustentabilidade" dos processos em escala local não é um objetivo mensurável } \\
\text { somente em termos ambientais, mas também em termos econômicos e culturais. }\end{array}$ \\
\hline
\end{tabular}

Fonte: Adaptado de Pollice (2010, p. 18-20).

Considerando as fortes relações entre a noção de território, identidade e desenvolvimento territorial com o que se espera das experiências de IG, é oportuno remeter esse debate à averiguação da sua prática.

\section{Questões de ordem metodológica e caracterização do objeto de estudo}

Para investigar as possíveis contribuições econômicas de uma Indicação Geográfica de produtos no desenvolvimento territorial, foram estudadas duas experiências de IG do setor vinícola, a Asprovinho, localizada no estado do Rio Grande do Sul, e a Progoethe, localizada ao sul do estado de Santa Catarina. Inicialmente foram realizados estudos bibliográficos sobre o tema Indicação Geográfica e demais temas conexos. Para a coleta de dados e informações sobre os dois casos, foram realizadas pesquisas documentais nos arquivos das associações, além de entrevistas com associados e dirigentes das duas associações que detêm o ato declaratório do INPI. Foi aplicado um questionário semiestruturado, ficando de fora apenas três associados de uma das experiências, por não estarem presentes quando da visita aos dois territórios estudados, durante os meses de julho de 2013. 
Na sequência, são caracterizadas as duas experiências objeto de estudo.

\subsection{Território do Vale da Uva Goethe}

A Indicação Geográfica da Uva Goethe está inserida na região sul do estado de Santa Catarina. De acordo com os dados do INPI, o Vale da Uva Goethe, está localizado entre as encostas da Serra Geral e o litoral sul catarinense nas Bacias do Rio Urussanga e Rio
Tubarão. Segundo dados da Progoethe, os limites nos vales formados pelas sub-bacias dos rios América, Caeté, Cocal, Carvão e Maior, que são afluentes do rio Urussanga e o vale principal desse mesmo rio, acrescidas das sub-bacias dos rios Lajeado, Molha, Armazém e Azambuja que fazem parte da bacia do rio Tubarão. A delimitação da área geográfica são os municípios de Urussanga, Pedras Grandes, Cocal do Sul, Morro da Fumaça, Treze de Maio, Orleans, Nova Veneza e Içara no Estado de Santa Catarina, conforme a figura 1.

Figura 1 - Municípios pertencentes à área delimitada dos Vales da Uva Goethe.

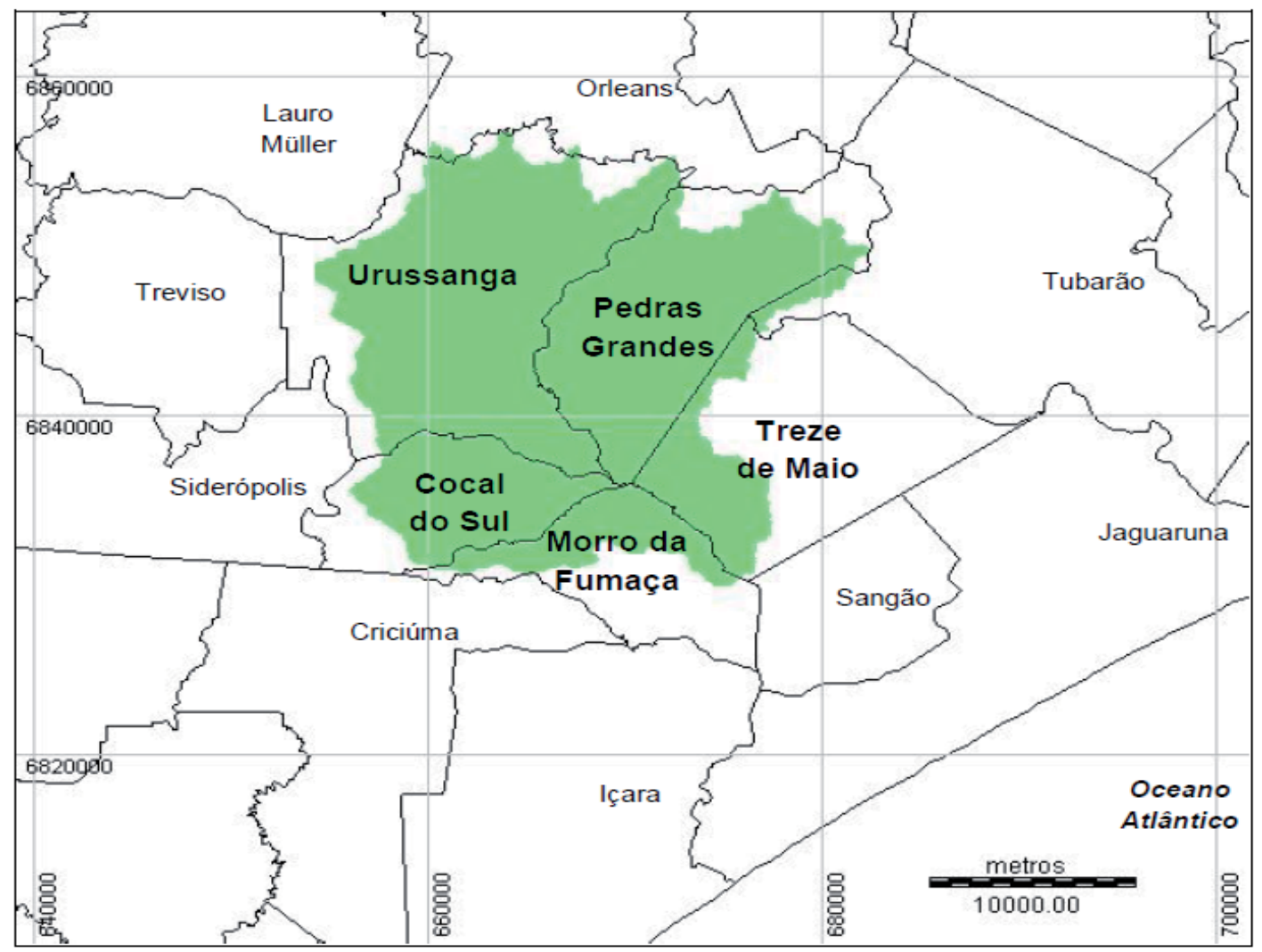

Fonte: Silva et al. (2011 apud VIEIRA; WATABABE; BRUCH, 2012, p. 336) (adaptado).

A fundação da Associação dos Produtores da Uva e do Vinho Goethe da Região de Urussanga (Progoethe) ocorreu em 05 de setembro de 2007. Dentre as características do vinho da Uva Goethe, bem como os fatores que contribuíram para que fosse possível receber o selo de Indicação Geográfica, destaca-se, além das particularidades técnicas do produto, o aspecto ligado à imigração italiana no século XIX, que consolidou junto ao INPI, a identidade dos "Vales da Uva Goethe", como um território único direcionado à produção dos vinhos Goethe. Esta foi a primeira Indicação Geográfica do estado de Santa Catarina, sendo considerado o único território a produzir tal variedade de uva em escala comercial, no mundo. A uva Goethe não é considerada uma uva fina ou uva vinífera. Classifica-se como uma uva americana. Seu conjunto é composto de uvas menos sofisticadas e, dessa forma, o preço de venda do vinho produzido com elas é inferior ao dos vinhos finos, porém possui um público consumidor específico. 


\subsection{Território do Vinho de Pinto Bandeira}

A Indicação Geográfica do Vinho de Pinto Bandeira, originalmente, estava localizada no município de Bento Gonçalves, além de 9\% em Farroupilha, no estado do Rio
Grande do Sul. No início de 2013, o Distrito de Pinto Bandeira emancipou-se de Bento Gonçalves, sendo que, a partir de então, a maior parte da IG se localiza neste novo município, conforme a Figura 2.

Figura 2 - Limites da região delimitada da IG Pinto Bandeira.

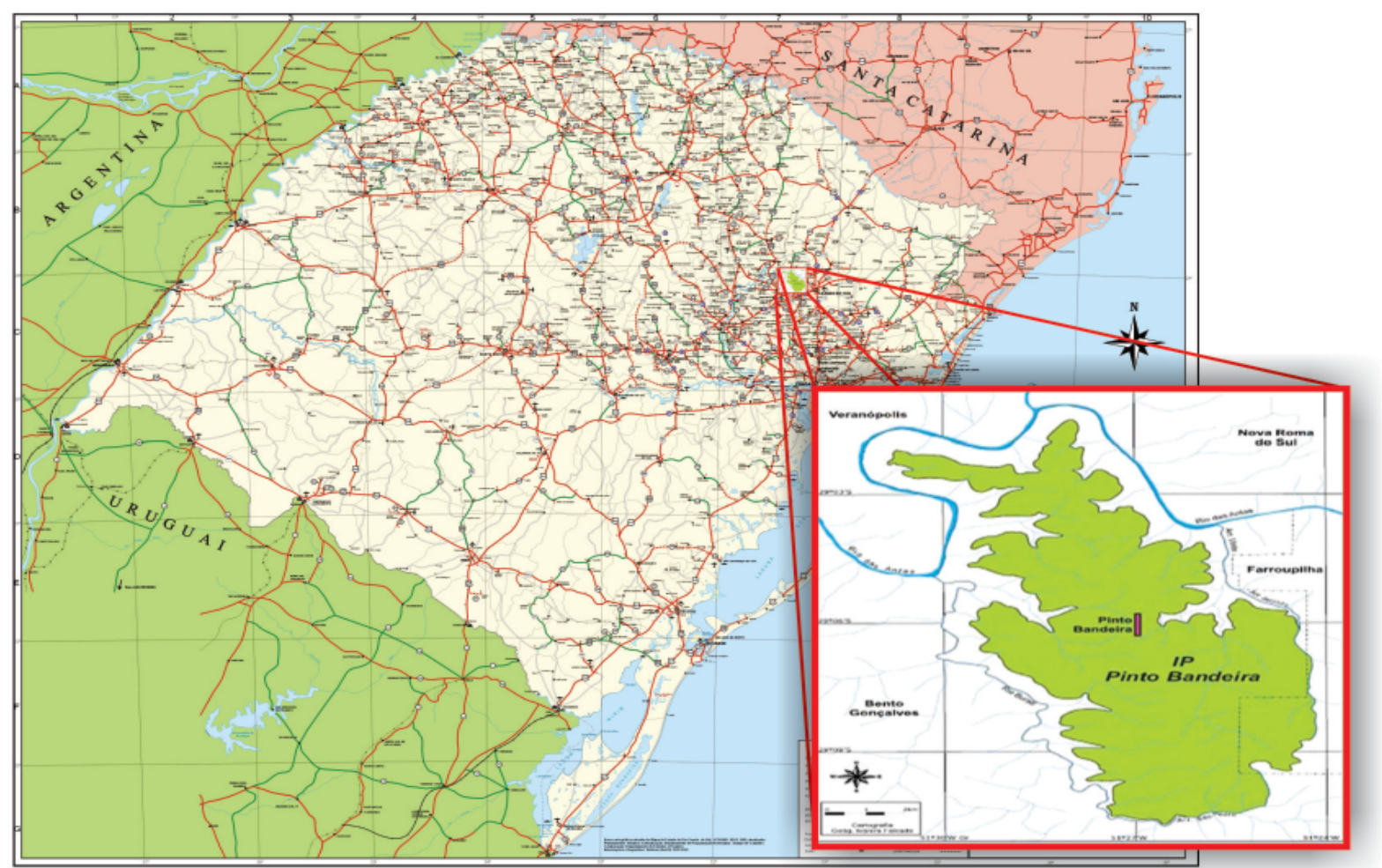

Fonte: Site da Asprovinho (Adaptado).

O município de Pinto Bandeira possui as vinícolas que fazem parte da IG, além de se destacar na produção de pêssego. Trata-se de um município essencialmente agrícola e com potencial para o turismo rural ou ecoturismo. No setor vinícola, além da tradição na produção de vinhos de regiões de altitude, a região detentora da IG destaca-se na industrialização de espumantes de qualidade.

A Associação dos Produtores de Vinhos de Pinto Bandeira (Asprovinho) foi criada em 29 de junho de 2001 e, segundo seus estatutos, tem com o objetivo proteger a natureza, a cultura local, os produtores de vinho e, sobretudo, preservar a qualidade e afirmar a identidade dos vinhos e espumantes produzidos no local. Os vinhos produzidos no território que detém o selo de IP são denominados "Vinhos Pinto Bandeira". O controle de qualidade é realizado pela Asprovinho, a qual contempla desde o cadastramento dos vinhedos e vinícolas, análises químicas, degustação e selo de controle.

\section{Resultados da investigação}

Para este estudo, a avaliação das experiências de IG em referência, além de todo arcabouço teórico, contou com a análise de informações documentais. Neste artigo, fazemos um recorte, considerando a percepção que os associados e dirigentes têm sobre a IG, a partir da análise do conteúdo das entrevistas, conforme a síntese que consta nos Quadros 2 e 3.

À esquerda dos quadros estão os aspectos focados pelas perguntas das entrevistas, tendo, à direita, uma síntese das respostas. 
Quadro 2 - Síntese das observações e análises das entrevistas com associados.

\begin{tabular}{|c|c|}
\hline Aspecto & Principais observações ou análises permitidas pela investigação \\
\hline $\begin{array}{l}\text { Os custos de produção } \\
\text { após a declaração de IG }\end{array}$ & $\begin{array}{l}\text { Para as vinícolas que estavam produzindo fora do Caderno de Normas, } \\
\text { houve o custo de adequação, além do fato de se obter uma conversão } \\
\text { menor de litros de vinho por kg de uva, para obter uma melhor qualidade. }\end{array}$ \\
\hline $\begin{array}{l}\text { Preço de venda após a } \\
\text { IG }\end{array}$ & $\begin{array}{l}\text { Foi possível perceber uma elevação do preço de venda, principalmente } \\
\text { em Urussanga. }\end{array}$ \\
\hline $\begin{array}{l}\text { A utilização do Mark-up } \\
\text { para a fixação do preço } \\
\text { de venda }\end{array}$ & $\begin{array}{l}\text { Em Pinto Bandeira, além dos custos de produção, impostos e lucro que } \\
\text { compõem o Mark-up são aliados aos fatores de mercado, no caso a per- } \\
\text { cepção de qualidade comparada a outros produtos, principalmente aos } \\
\text { importados. No vinho Goethe, além da definição do preço pelo Mark-up, } \\
\text { é observado o valor de mercado. }\end{array}$ \\
\hline $\begin{array}{l}\text { Participação dos } \\
\text { produtos com IG em } \\
\text { relação à produção total }\end{array}$ & $\begin{array}{l}\text { Identificou-se uma pequena parcela da produção com selo de IG e em } \\
\text { alguns casos nenhum produto com selo. }\end{array}$ \\
\hline $\begin{array}{l}\text { Impacto do projeto de } \\
\text { Indicação Geográfica }\end{array}$ & $\begin{array}{l}\text { No território da Progoethe, constatou-se uma expectativa de retorno fi- } \\
\text { nanceiro com a agregação de valor aos produtos e a padronização da } \\
\text { qualidade. No território de Pinto Bandeira, o principal argumento é a } \\
\text { visibilidade, a força do conjunto e o objetivo de obter uma DO. }\end{array}$ \\
\hline $\begin{array}{l}\text { O diferencial para os } \\
\text { produtos com IG }\end{array}$ & $\begin{array}{l}\text { Para grande parte dos associados, o maior problema está no aspecto de } \\
\text { o consumidor brasileiro ter pouca informação sobre o que significa um } \\
\text { selo de IG e como são controlados os produtos que irão receber este selo. }\end{array}$ \\
\hline $\begin{array}{l}\text { A importância do } \\
\text { turismo na Indicação } \\
\text { Geográfica }\end{array}$ & $\begin{array}{l}\text { O turismo é tido como um ponto de extrema relevância para o sucesso } \\
\text { da IG, uma estratégia de Marketing e divulgação dos produtos. É pelo } \\
\text { turista que os produtos são levados a outros centros consumidores, que } \\
\text { se interessam pelo produto e pela região, indicando-os a outras pessoas. }\end{array}$ \\
\hline $\begin{array}{l}\text { A importância das } \\
\text { Associações }\end{array}$ & $\begin{array}{l}\text { Na opinião dos produtores, fica evidente que foi pela união de esforços } \\
\text { em uma associação que o processo da obtenção da IG se consolidou. }\end{array}$ \\
\hline $\begin{array}{l}\text { A IG e o } \\
\text { desenvolvimento de um } \\
\text { território }\end{array}$ & $\begin{array}{l}\text { A pesquisa permitiu concluir que só a estruturação da IG não consegue } \\
\text { desenvolver o território, depende de outros fatores associados, com des- } \\
\text { taque para o turismo como forma de divulgação do produto. O desen- } \\
\text { volvimento é complexo e necessita de um conjunto de ações por parte da } \\
\text { sociedade e do poder público na busca de vetores de desenvolvimento e } \\
\text { certamente a IG é um destes vetores, não o único. }\end{array}$ \\
\hline $\begin{array}{l}\text { O mercado para o ramo } \\
\text { da vinicultura }\end{array}$ & $\begin{array}{l}\text { Em geral, existe um excedente de uva no mercado. Este faz com que o } \\
\text { preço pago ao produtor seja baixo. Para as vinícolas, o maior problema } \\
\text { são os vinhos importados com tributação diferenciada. A substituição tri- } \\
\text { butária do ICMS também gera um desequilíbrio de caixa, pois o imposto } \\
\text { será recolhido por ocasião da venda. }\end{array}$ \\
\hline
\end{tabular}

Fonte: Dados da pesquisa (2013).

No Quadro 3 está uma síntese das entrevistas com os dirigentes das associações.

Quadro 3 - Observações e análises das entrevistas com dirigentes das associações.

\begin{tabular}{|l|l|}
\hline \multicolumn{1}{|c|}{ Aspecto } & \multicolumn{1}{|c|}{ Principais observações ou análises permitidas pela investigação } \\
\hline $\begin{array}{l}\text { A IG e o desenvolvimento de } \\
\text { um território }\end{array}$ & $\begin{array}{l}\text { A opinião de todos é unânime, que a IG é sim uma alternativa para } \\
\text { o desenvolvimento do território, contribuindo para a agregação de } \\
\text { valor à cadeia produtiva e ao comércio local, mas que a IG sozinha } \\
\text { não é capaz de desenvolver um território, depende de outros fatores } \\
\text { e deve estar aliada ao turismo, pois irá compor a cesta de serviços } \\
\text { oferecidos ao turista. }\end{array}$ \\
\hline $\begin{array}{l}\text { As estratégias de marketing } \\
\text { das Associações para } \\
\text { divulgar a IG }\end{array}$ & $\begin{array}{l}\text { As associações vêm participando de eventos e feiras, firmando par- } \\
\text { cerias com organizações de forma a demonstrar o que é uma Indica- } \\
\text { ção Geográfica. }\end{array}$ \\
\hline
\end{tabular}




\begin{tabular}{|l|l|}
\hline \multicolumn{1}{|c|}{ Aspecto } & \multicolumn{1}{|c|}{ Principais observações ou análises permitidas pela investigação } \\
\hline $\begin{array}{l}\text { O turismo da região com fator } \\
\text { de divulgação dos produtos } \\
\text { com certificação de IG }\end{array}$ & $\begin{array}{l}\text { A importância do turismo no processo de divulgação de uma IG } \\
\text { também é voz corrente entre as associações e não apenas uma opi- } \\
\text { nião dos vinicultores. }\end{array}$ \\
\hline $\begin{array}{l}\text { Interesse de outras pessoas } \\
\text { em fazer parte da associação } \\
\text { após a declaração de IG }\end{array}$ & $\begin{array}{l}\text { Houve interesse de outros empreendimentos, principalmente os li- } \\
\text { gados ao turismo, o que demonstra de forma clara que a IG é uma } \\
\text { alternativa para o desenvolvimento territorial e para o crescimento } \\
\text { do comércio local. }\end{array}$ \\
\hline $\begin{array}{l}\text { Ações para motivar os } \\
\text { associados a buscar a } \\
\text { certificação de IG }\end{array}$ & $\begin{array}{l}\text { A visibilidade do produto e os benefícios de uma IG foram os princi- } \\
\text { pais aspectos utilizados pelas associações. }\end{array}$ \\
\hline $\begin{array}{l}\text { Registros quanto ao volume } \\
\text { de produção dos associados }\end{array}$ & $\begin{array}{l}\text { Atualmente o controle sobre a produção e os benefícios gerados é } \\
\text { reduzido, pois haverá apenas o controle sobre o volume de produção } \\
\text { com selo de IG. }\end{array}$ \\
\hline $\begin{array}{l}\text { Perspectivas de exportação } \\
\text { dos produtos com IG }\end{array}$ & $\begin{array}{l}\text { Não existe previsão, e, na visão da Asprovinho, o fator limitador é } \\
\text { a carga tributária do produto, que o torna muito caro no mercado } \\
\text { internacional. }\end{array}$ \\
\hline
\end{tabular}

Fonte: Dados da pesquisa (2013).

Os dois quadros resumem as principais percepções dos entrevistados quanto à interrogação que originou a presente investigação. Para finalizar, são feitas algumas considerações, sintetizando as principais análises permitidas pelo estudo realizado.

\section{Considerações finais}

O objetivo desta pesquisa foi analisar a contribuição econômica da Indicação Geográfica de produtos no desenvolvimento territorial, pela realização de estudos bibliográficos e documentais, visitação às experiências e realização de entrevistas.

A dimensão econômica foi tratada no universo do desenvolvimento territorial, uma vez que a Indicação Geográfica representa a delimitação de um espaço territorial com especificidade. Assim, a IG se constitui, segundo as normas brasileiras, em um ato declaratório que, de acordo com sua tipologia, será uma Indicação de Procedência ou uma Denominação de Origem.

A IG no Brasil está em um processo de expansão e, ao mesmo tempo, de estruturação, pois muitas delas estão se constituindo no decorrer dos últimos cinco anos. Nos dois territórios estudados, foram encontradas situações diversas, pois uma das experiências já está comercializando os produtos, e a outra iniciará em 2014 a comercialização da primeira safra. Nesse contexto, os aspectos econômicos precisaram ser analisados não apenas pelo ganho em escala de produção, mas também pelas expectativas de possíveis impactos econômicos no desenvolvimento territorial.

Ao analisar o volume de produção, verificou-se que os produtos com IG apresentam valores pouco representativos em relação ao total das receitas. A pouca relevância entre o volume de produção com certificação de IG em relação ao total produzido, não chega a ser uma restrição à importância da IG, mas sim uma questão de mercado, pois nas regiões pesquisadas os produtos com IG são vinhos brancos e espumantes, ao passo que o mercado consome mais vinhos tintos. Assim, verifica-se que os produtos com IG compõem o mix de produtos da vinícola, onde existem produtos de menor valor e com maior volume de vendas e produtos diferenciados com valor maior, no caso os produtos com IG. Nas vinícolas pesquisadas, ficou evidente que os produtos com IG são destinados a um público mais seletivo, sendo que são mais significativos os reflexos indiretos, favorecendo aos demais produtos em função da visibilidade que a IG proporciona.

A análise dos dois casos estudados revela que é pelo turismo a principal forma através da qual os produtos com IG são reconhecidos fora de seu território. Da mesma forma, uma região que pensa em desenvolver o turismo, ao buscar evidenciar seus atributos, deve considerar que estes podem estar associados a produtos com IG. Desse modo, 
observa-se uma relação muito próxima entre a IG e o turismo, o que certamente favorecerá o desenvolvimento do território, com a integração dessas duas estratégias de desenvolvimento territorial. A relação intrínseca entre turismo e IG é descrita por Nascimento, Nunes e Bandeira (2012, p. 380):

A aliança entre turismo e Indicação Geográfica propicia o reconhecimento de culturas tradicionais, a valorização da gastronomia típica, produção sustentável de alimentos, proteção dos manuseios artesanal e cultural.

Outro aspecto a destacar está relacionado à identidade territorial, que é a busca de atributos do território, que podem estar relacionados com aspectos geográficos, históricos ou por um tipo de produto ou sabor especial. A busca na identificação desses atributos é o esforço dos atores sociais do território na trajetória do seu desenvolvimento. Em ambas as experiências visitadas, foi possível observar no aspecto prático a importância desses atores sociais.

Os resultados obtidos dão conta de um considerável entrosamento entre a existência de uma IG e a promoção socioeconômica e cultural do território atingido, como um processo de benefício mútuo. Esse argumento foi evidenciado quando perguntado sobre o interesse de outras pessoas em se associarem após a certificação de IG. Verificou-se que houve a integração de empresas e pessoas ligadas ao setor de serviço, mais precisamente, dos serviços de atendimento aos turistas. Constatou-se então que os turistas vêm em busca do produto com IG e, por conseguinte, consomem diferentes produtos e serviços, trazendo benefícios econômicos para outros empreendimentos locais. Entende-se, então, que a IG é uma estratégia que, mesmo sendo exclusividade das pessoas que detêm o direito ao uso do selo, torna-se inclusiva, pois gera benefícios indiretos a outros setores da economia.

A Indicação Geográfica, como já fora citada na revisão bibliográfica, é um processo de construção coletiva que visa beneficiar a um território, seja diretamente aos produtores envolvidos na IG, seja pelo benefício indireto ao comércio local. Com os estudos realizados, ficou evidenciado que a IG gera mais benefícios indiretos para o desenvolvimento territorial do que diretos, implicando a neces- sidade da integração com os outros setores da economia local. Dessa forma, o primeiro passo da IG é a união de pessoas em torno de um objetivo coletivo.

Portanto pode-se dizer que a IG gera encadeamentos para frente e para trás, impactando no desenvolvimento territorial. No caso do vinho, essa cadeia produtiva envolve de forma descendente, a partir das vinícolas, os produtores, e estes as empresas, principalmente as que comercializam insumos agrícolas. De forma ascendente, partindo da vinícola para o setor de transporte e deste com o setor de serviços (combustíveis, autopeças etc.). De forma lateral, tem-se o turismo, este capaz de gerar um novo desencadeamento. Poderia ainda se dizer que os produtos com IG, conforme propõe a teoria dos polos de crescimento, seriam a indústria motriz, capaz de desenvolver outras atividades em seu entorno.

É possível concluir, então, que, quando um território possui um produto ou serviço com diferencial e que este possa ser declarado como IG, são gerados impactos não somente aos produtores e à cadeira produtiva ligada ao produto com IG, mas para todo território circundante. Assim, a hipótese levantada: se os produtos que possuem Indicação Geográfica são capazes de gerar um incremento no preço de venda e, com isso, contribuir para a agregação de renda e ainda corroborar economicamente o desenvolvimento territorial. Conclui-se que esta se confirmou. No entanto os benefícios não estão simplesmente relacionados a um incremento de preço, pois os resultados econômicos para o território são bem superiores. Além da elevação dos preços de venda dos produtos com IG, os demais produtos similares também obtêm um ganho econômico, além dos demais setores da sociedade.

Por fim, como recomendação, entende-se que a divulgação na mídia de massa sobre o que é uma IG representaria um grande impulso para a busca de produtos e serviços com diferencial, com contributos no desenvolvimento dos territórios. O consumidor, no caso do vinho, tem uma preferência pelos importados, principalmente pela fama de vinhos de qualidade superior, discurso construído pela mídia de massa. Utilizar esses mesmos meios para evidenciar que os 
produtos nacionais com selo de IG são produtos de qualidade e que são certificados, faria com que a visibilidade tão pretendida pelos produtores de vinho das duas regiões pudesse ser atingida.

Os estudos nas duas regiões devem ser ampliados, por exemplo, para avaliar se, com o passar do tempo, as expectativas dos produtores da Uva Goethe se confirmam com o aumento da produção e agregação de valor ao produto, assim podendo gerar maior renda aos produtores e vinícolas. Da mesma forma, em Pinto Bandeira, avaliar a aspiração de, se for declarada uma DO, esta trazer maiores impactos territoriais do que a declaração de IP. São estudos que merecem ser realizados no futuro.

\section{Referências}

Associação dos Produtores de Vinhos de Pinto Bandeira (ASPROVINHO). Vinhos de Pinto Bandeira, [s.d.]. Disponível em: <http://www.asprovinho.com.br/ index.php?option $=$ com_content\&task=view\&id $=2 \& I t$ emid=3>. Acesso em: 10 abr. 2013.

BOECHAT, A. M. F.; ALVES, Y. B. O uso da Indicação Geográfica para o Desenvolvimento Regional: o caso da carne do Pampa Gaúcho. In: ENCONTRO INTERNACIONAL DE PRODUÇÃO CIENTÍFICA CESUMAR (EPCC), 2011, Maringá. Anais eletrônicos... Maringá: Cesumar, 25 a 28 out. 2011.

BRASIL. Instituto Nacional da Propriedade Industrial. Registros: Indicação Geográfica. Rio de Janeiro, 2014. Disponível em: <http://www.inpi.gov.br/ images/ docs/lista_com_as_indicacoes_geograficas_concedidas_-_31-12-2013.pdf>. Acesso em: 25 jan. 2014.

BRASIL. Lei $n^{\circ}$ 9.279, de 14 de maio de 1996. Regula direitos e obrigações relativos à propriedade industrial. Brasília, DF: Presidência da República/Casa Civil/ Subchefia para Assuntos Jurídicos, 2006.

DALLABRIDA, V. R. Governança Territorial: o debate teórico, desafios e proposta metodológica para avaliação de sua prática. Lisboa: Instituto de Ciências Sociais/ Universidade de Lisboa, 2014. [Inédito].

DALLABRIDA, V. R.; FERNÁNDEZ, V. R. Desenvolvimento territorial: possibilidades e desafios, considerando a realidade de âmbitos espaciais periféricos. Passo Fundo: Ed, UPF; Ijuí: Ed. UNIJUI, 2008.

FERREIRA, A. M. et al. Indicação Geográfica no Brasil: aspectos legais. In: DALLABRIDA, V. R. (Org.). Território, identidade territorial e desenvolvimento regional: reflexões sobre Indicação Geográfica e novas possibilidades de desenvolvimento com base em ativos com especificidade territorial. São Paulo: LiberArs, 2013. p. 127-134.

GOLLO, S. S.; CASTRO, A. W. V. Indicações geográficas: o processo de obtenção da indicação de procedência Vale dos Vinhedos Serra gaúcha/RS/Brasil. In:
CONGRESSO DA SOBER, 45., 2007, Londrina. Anais... Londrina: SOBER, 2007.

GONTIJO, C. As transformações do sistema de patentes, da Convenção de Paris ao Acordo Trips: a posição brasileira. Berlin: FDCL/Gneisenaustr.2a, 2005.

HAESBAERT, R. Concepções de território para entender a desterritorialização. In: SANTOS, M. et al. Território, territórios: ensaios sobre o ordenamento territorial. 3.ed. Rio de Janeiro: Lamparina, 2007. p. 44-71.

. O mito da desterritorialização: do "fim dos territórios" à multi-territorialidade. Rio de Janeiro: Bertrand Brasil, 2004.

Regional-global: dilemas da região e da regionalização na geografia contemporânea. Rio de Janeiro: Bertrand Brasil, 2010.

BRASIL. Instituto Nacional da Propriedade Industrial. Registros: Indicação Geográfica. Rio de Janeiro, 2014. Disponível em: <http://www.inpi.gov.br/ images/ docs/lista_com_as_indicacoes_geograficas_concedidas_-_31-12-2013.pdf>. Acesso em: 25 jan. 2014.

JEZIORNY, D. L. Território vale dos vinhedos. Instituições, indicações geográficas e singularidade na vitivicultura da Serra Gaúcha. 2009. Dissertação (Mestrado em Economia) - Universidade Federal de Uberlândia, Uberlândia, 2009.

KAKUTA, S. M.; SOUZA, A. I. L.; SCHWANKE, F. H.; GIESBRECHT, H. O. Indicações geográficas: guia de respostas. Porto Alegre: SEBRAE/RS, 2006.

NASCIMENTO, J. S.; NUNES, G. S.; BANDEIRA, M. G. A. A importância de uma indicação geográfica no desenvolvimento do turismo de uma região. Revista GEINTEC, São Cristóvão, SE, v. 2, n. 4, p. 378-386, 2012.

PIMENTEL, L. O. Os desafios dos aspectos legais na prática de estruturação das Indicações Geográficas. In: DALLABRIDA, V. R. (Org.). Território, identidade territorial e desenvolvimento regional: reflexões sobre Indicação Geográfica e novas possibilidades de desenvolvimento com base em ativos com especificidade territorial. São Paulo: LiberArs, 2013. p. 135-143.

POLLICE, F. O papel da identidade territorial nos processos de desenvolvimento local. Tradução de Andrea Galhardi de Oliveira, Renato Crioni, Bernadete Aparecida Caprioglio de Castro Oliveira. Espaço e cultura, Rio de Janeiro, n. 27, p. 7-23, jan./jun. 2010.

PROGOETHE. Histórico. Urussanga, SC, 2012. Disponível em: <http://www.progoethe.com.br/historico. php?id=1>. Acesso em: 06 abr. 2013.

SACCO DOS ANJOS, F. et al. Sobre 'efígies e esfinges': indicação geográfica, capital social e desenvolvimento territorial. In: DALLABRIDA, V. R. (Org.). Território, identidade territorial e desenvolvimento regional: reflexões sobre Indicação Geográfica e novas possibilidades de desenvolvimento com base em ativos com especificidade territorial. São Paulo: LiberArs, p. 159-196, 2013.

SAQUET, M. A.; SILVA, S. S. Milton Santos: concepções de geografia, espaço e território. Geo UERJ, Rio de Janeiro, ano 10, v. 2, n. 18, p. 24-42, jul./ dez. 2008. 
SANTOS, M. A natureza do espaço: técnica e tempo - razão e emoção. São Paulo: Hucitec, 1996.

SANTOS, M. et al. Território, territórios: ensaios sobre o ordenamento territorial. 3.ed. Rio de Janeiro: Lamparina, 2007.

SOUZA, M. J. L. O território: sobre espaço e poder á autonomia e desenvolvimento. In: CASTRO, I. E.; GOMES,
P. C. C.; CORRÊA, R. L. (Org.). Geografia: conceitos e temas. Rio de Janeiro: Bertrand Brasil, 2001. p. 77-116.

VIEIRA, A. C. P.; WATABABE, M.; BRUCH, K. L. Perspectivas de desenvolvimento da vitivinicultura em face do reconhecimento da Indicação de Procedência Vales da Uva Goethe. Revista GEINTEC, São Cristóvão, SE, v. 2, n. 4, p. 327-343, 2012. 